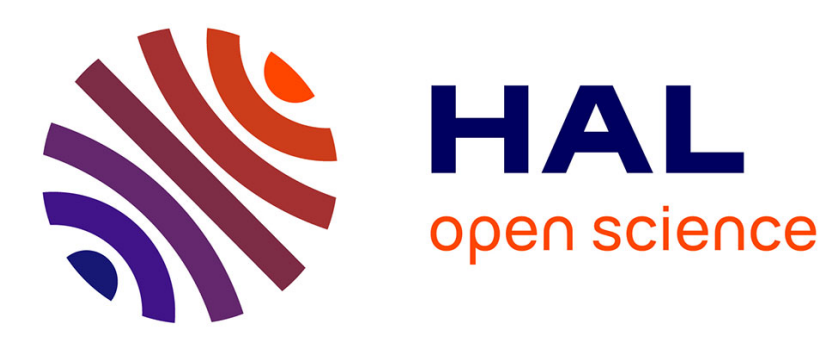

\title{
Experimental study on air cooling by spray in the upstream flow of a heat exchanger
}

Julien Tissot, Pascal Boulet, Alexandre Labergue, Guillaume Castanet, François Trinquet, Laurence Fournaison

\section{- To cite this version:}

Julien Tissot, Pascal Boulet, Alexandre Labergue, Guillaume Castanet, François Trinquet, et al.. Experimental study on air cooling by spray in the upstream flow of a heat exchanger. International Journal of Thermal Sciences, 2012, 60, pp.23 - 31. 10.1016/j.ijthermalsci.2012.06.005 . hal-01570476

\section{HAL Id: hal-01570476 \\ https://hal.univ-lorraine.fr/hal-01570476}

Submitted on 30 Jul 2017

HAL is a multi-disciplinary open access archive for the deposit and dissemination of scientific research documents, whether they are published or not. The documents may come from teaching and research institutions in France or abroad, or from public or private research centers.
L'archive ouverte pluridisciplinaire HAL, est destinée au dépôt et à la diffusion de documents scientifiques de niveau recherche, publiés ou non, émanant des établissements d'enseignement et de recherche français ou étrangers, des laboratoires publics ou privés. 


\title{
Experimental study on air cooling by spray in the upstream flow of a heat exchanger
}

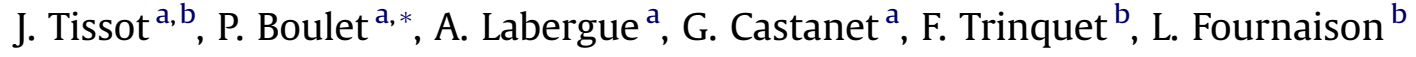 \\ a Nancy Université, LEMTA, CNRS, Faculté des Sciences et Techniques, BP 70239, Vandoeuvre les Nancy cedex 54506, France \\ ${ }^{\mathrm{b}}$ Laboratoire de Génie des Procédés pour l'Environnement, l'Energie et la Santé (LGP2ES - EA21), Cnam-Cemagref, GPAN, 1rue Pierre-Gilles de Gennes - CS10030, \\ 92761 Antony Cedex, France
}

\section{Keywords: \\ Spray \\ Cooling \\ Evaporation \\ Heat transfer}

\begin{abstract}
A B S T R A C T
An experimental study has been carried out on a water sprayed air flow aimed at cooling the air upstream of a heat exchanger in order to improve the heat transfer. A pilot has been built allowing injecting droplets in air in various conditions while controlling flow rates, temperature and humidity. The emphasis has been put on the spray evaporation resulting in a temperature decrease and humidity increase in the air flow. An actual increase in the heat exchanged (up to 3 times more) for an air initially entering in surrounding conditions (temperature between 293 and $308 \mathrm{~K}$ and relative humidity between 47.5\% and 19.7\%) has been reached when injecting upstream droplets smaller than $25 \mu \mathrm{m}$, in an air flow crossing the exchanger. A validation of a numerical study on the heat exchanges in the air flow has been also achieved. Results will be applied for the optimization of the water flow providing the best compromise between heat exchanged and water consumption.
\end{abstract}

\section{Introduction}

The efficiency of a refrigerating unit highly depends on the quality of the heat transfer occurring at the condenser. Then, adding a water spray in the air flow upstream of a condenser can increase the heat exchange, as it has been shown for exchangers $[1,2]$ or even condensers involved in refrigeration applications [3-6]. Indeed, lowering the air temperature with the evaporation of water may help to improve the heat exchange at the condenser and may consequently decrease the condensing temperature. This could be especially useful in the case of hot and dry surrounding conditions. This decrease in condensing temperature will result in a lower compression work and a higher cooling capacity. A logical and expected consequence would be a higher coefficient of performance for the machine. However, the optimization of such a system regarding the best injection solution and the water consumption is still a real issue. One of the challenges is the selection of a nozzle providing the right droplet size distribution and volumetric fraction in order to cool the air flow more efficiently. The Cemagref (research center in Antony, France) and the LEMTA (research laboratory in Nancy, France) have undertaken an experimental study aimed at defining the most efficient cooling

\footnotetext{
* Corresponding author.

E-mail address: pascal.boulet@lemta.uhp-nancy.fr (P. Boulet).
}

and loading in humidity, without excess of liquid water under the form of droplets or deposition on the wall in the downstream flow (in order to avoid any problem of potential bacteriological development).

The present study has been prepared numerically [7] in a previous work, which showed that droplets with size below $25 \mu \mathrm{m}$ are more suitable for the application of interest. If the smallest droplets may promote the evaporation when considered as individual inclusions, the numerical simulation has demonstrated that a collection of droplets should have a sufficient inertia to generate a large cooling surface. Indeed, when simulating the injection of very small droplets, the authors observed a trend toward a small concentrated volume where the air relative humidity quickly rises up to saturation, whereas the outside of this restricted area is not affected by the droplet injection. On the contrary, larger droplets affect a larger area but are known to be less efficient than the smallest ones - given the same liquid water volume - regarding evaporation ability. A compromise has to be found between small droplets with high evaporation ability and large droplets better aimed at influencing a large area due to their inertia. This was the starting point of the present experimental work. An experimental setup has been built, based on an instrumented air duct with a stabilized air flow in which droplets are injected using a nozzle (a hydraulic high pressure nozzle as it will be explained below). 
The present contribution is consequently focused on the experimental part aimed at the validation of the concept of possible cooling of air, the choice of a dedicated nozzle for optimizing the process and the quantification of temperature decrease and humidity loading of air. Then, the solution will be integrated in a complete pilot aimed at studying the energy exchanges in an actual refrigerating machine.

In the following sections, the experimental setup will be fully described, as well as measurement devices, corresponding uncertainties and nozzle selection. Then, effective cooling will be studied and analysed in terms of air temperature and humidity. Finally, a first result will be discussed on the heat exchange improvement in the heat exchanger crossed by the flow.

\section{Experimental setup}

\subsection{The experimental pilot}

The experimental pilot is illustrated in Fig. 1a and b shows a picture of the actual device. The air flow is pre-heated at the inlet on the left hand side of Fig. 1a and sucked in a cylindrical pipe. A flowmeter allows the measurement of the inlet flow rate. Two honeycomb grids are located after the blower in order to provide a settled and stationary flow. The air is then entering in the channel section devoted to study the interactions between the air flow and the droplets. Droplets are injected with a spray nozzle (either in cocurrent or counter-current directions) and the air-droplet flow is directed toward the heat exchanger at the right hand side of Fig. 1a and b. Hygrometers and thermocouples allow the characterization of the air properties. Flowmeter and thermocouples may also be used for the evaluation of the heat exchanged at the exchanger by characterizing the properties of the fluid inside the exchanger (water for the work reported here). The main part of the device for the present study is the channel with rectangular section $36 \times 25 \mathrm{~cm}^{2}$ and a length of $1.7 \mathrm{~m}$. The whole device is located in a room where the temperature and the humidity are controlled. Typical trajectories of droplets are presented on Fig. 2a, taken from a similar preliminary study as the one reported in [7]. On Fig. 2a, droplets are injected in a co-current direction: air and water droplets are flowing from the left to the right in the channel. On Fig. 2b, droplets are injected in a counter-current direction (from the right to the left at position $X=0.5 \mathrm{~m}$ ), but the counter flow of air causes a strong drag effect which slows them and carries droplets in the reverse direction, downstream toward the exchanger. Actually, the trajectories plotted here for a better understanding of the co-current and counter-current configurations correspond to computations carried out with the code MIRABELLES [7]. Fifty typical trajectories of droplets with size $25 \mu \mathrm{m}$ have been selected for the present illustration. They are extracted from the complete statistics performed on the dispersed phase, injected in a cone with angle $72^{\circ}$, with initial temperature $298 \mathrm{~K}$ and initial velocity of $10 \mathrm{~m} / \mathrm{s}$, tracked in a channel with the same size as the pilot, with air entering in the channel at surrounding conditions $298 \mathrm{~K}-5.5 \mathrm{~g}$ of water $/ \mathrm{kg}$ of air and average velocity of $1 \mathrm{~m} / \mathrm{s}$. Owing to the differences in the spray dispersion, consequences are expected on the heat and mass exchange, resulting in discrepancies in air temperature cooling and in the humidity loading of air. On Fig. 2 the trajectories are colored as a function of the droplet temperature in the channel. The differences in the cooling process are obvious according to the numerical prediction: droplets are dispersed on a wider section in counter-current situation and experience a stronger temperature decrease. As a consequence, higher cooling

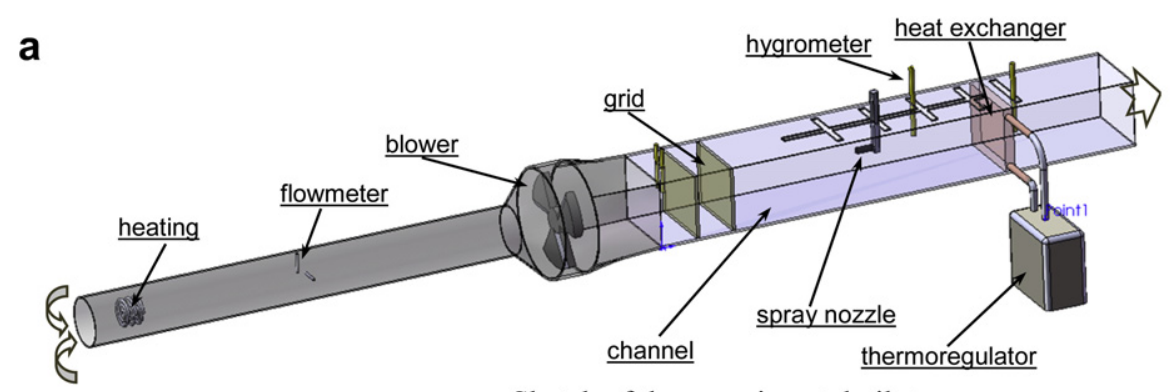

Sketch of the experimental pilot

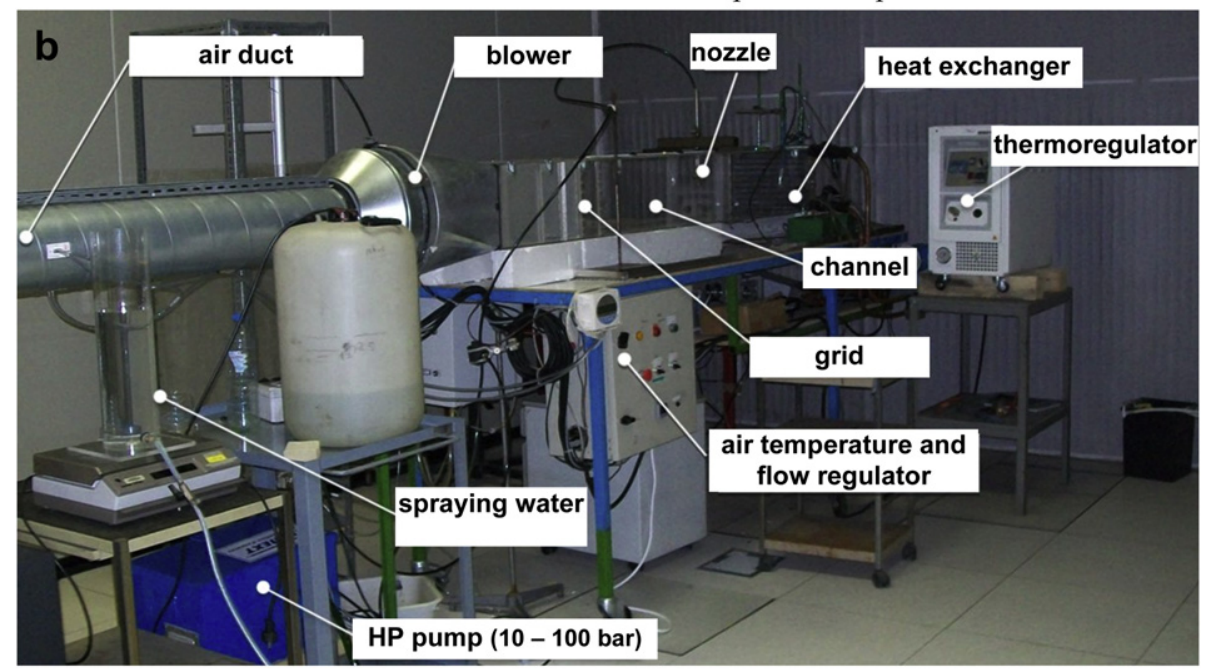

Picture of the pilot

Fig. 1. Experimental setup. 


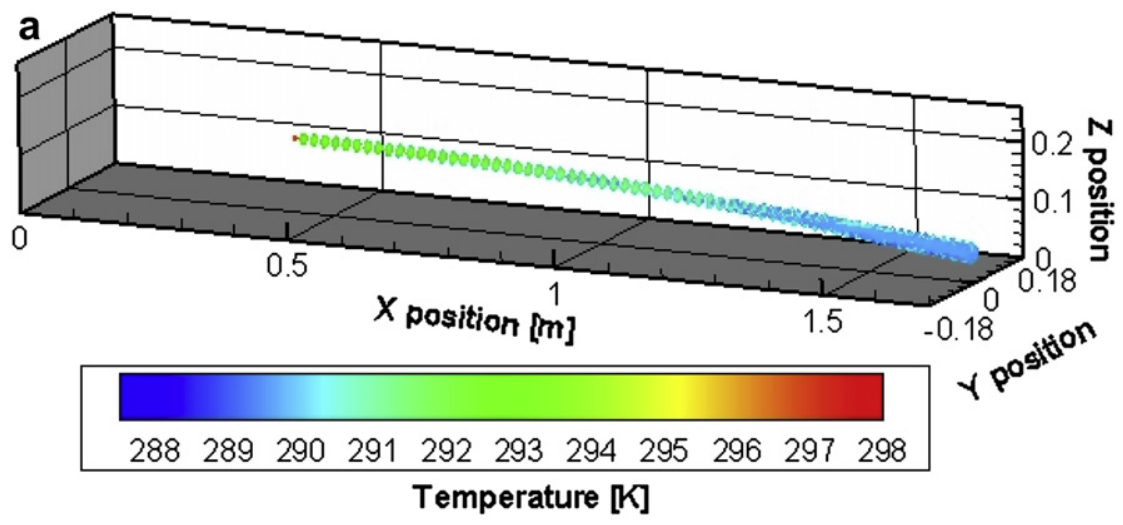

b Co-current injection.

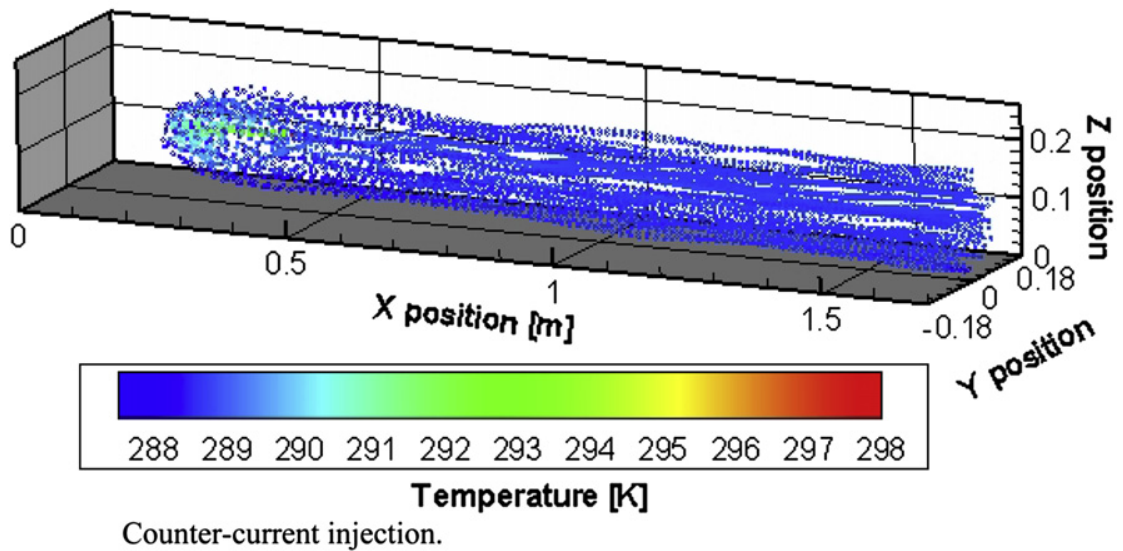

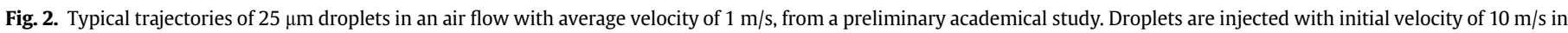
a cone with angle $72^{\circ}$ in co-current direction (Fig. 2a) and counter-current direction (Fig. 2b).

efficiency is expected in counter-current situation as already discussed in [7]. The experimentations should confirm these predictions.

\subsection{Measurements, uncertainties}

Various characteristics (flow rate, velocity, temperature, humidity) are determined experimentally through dedicated measurement devices, which are listed with their related uncertainties in Table 1. The type of the measurement device is given with its range of application, the accuracy according to the manufacturer, the evaluated accuracy after calibration and also after dedicated uncertainty evaluation (details are available in [8]). Finally, the actual dispersion of the measurements considering all the experimental campaigns including repeatability tests is provided in the last column. The air flowmeter is used for the evaluation of the upstream air flow rate. A weigh-scale allows the determination of the water flow rate through an analysis of the continuous weighting of the water tank. Thermocouples are used for a scan of the temperature distribution in the air-droplet flow. A virtual grid of temperature measurements has been considered in transverse sections, with temperatures measured every $3 \mathrm{~cm}$ for a complete mapping of half of the channel section (owing to the symmetry property), corresponding to 56 measurement points for a given transverse section. Finally, the hygrometer allows a direct determination of the humidity. Both hygrometers and thermocouples are protected from a direct wetting by droplets by using a dedicated shield. The homogeneity of the velocity in the channel

Table 1

Apparatuses involved in the measurement chain and related uncertainties.

\begin{tabular}{|c|c|c|c|c|c|}
\hline Apparatus & Range of application & $\begin{array}{l}\text { Range used in the } \\
\text { present study }\end{array}$ & $\begin{array}{l}\text { Accuracy according } \\
\text { manufacturer }\end{array}$ & $\begin{array}{l}\text { Evaluated accuracy } \\
\text { after calibration }\end{array}$ & $\begin{array}{l}\text { Dispersion of the } \\
\text { performed measurements }\end{array}$ \\
\hline $\begin{array}{l}\text { Airflow meter } \\
\text { Kimo ref: CP200 }\end{array}$ & $94.2 \rightarrow 3141 \mathrm{~L} / \mathrm{h}$ & $100 \rightarrow 250 \mathrm{~L} / \mathrm{h}$ & $+1-3 \%$ & No calibration & $\sim 1.5 \%$ \\
\hline $\begin{array}{l}\text { Balance Mettler } \\
\text { ref: PE24 }\end{array}$ & $0 \rightarrow 24 \mathrm{~kg}$ & $0 \rightarrow 6 \mathrm{~kg}$ & $+/-1 \mathrm{~g}$ & $+/-1 \mathrm{~g}$ & $2 \mathrm{~g}$ \\
\hline $\begin{array}{l}\text { Thermocouple } \\
\text { TCSA de type } \\
\text { T ref: B10-TX }\end{array}$ & $198 \rightarrow 523 \mathrm{~K}$ & $288 \rightarrow 313 \mathrm{~K}$ & $+/-0.5 \mathrm{~K}$ & $+1-0.03 \mathrm{~K}$ & $0.1 \mathrm{~K}$ \\
\hline $\begin{array}{l}\text { Hygometer Vaisala } \\
\text { ref: } 50 \mathrm{Y}\end{array}$ & $\begin{array}{l}10 \% \rightarrow 90 \% 263 \\
K \rightarrow 313 \mathrm{~K}\end{array}$ & $\begin{array}{l}10 \% \rightarrow 90 \% 283 \\
K \rightarrow 313 \mathrm{~K}\end{array}$ & $+1-5 \%$ & $+1-1 \%$ & $1.2 \%$ \\
\hline
\end{tabular}


has been checked prior to the heat transfer study, using an anemometer and a sweeping in all the transverse section at the inlet of the studied area.

\subsection{Nozzle selection}

The nozzle is one of the key elements of the experimental setup. The goal is to inject droplets so as to provide a strong evaporation affecting the largest transverse section as possible. The preliminary numerical study [7] has provided the conclusion that the best efficiency was obtained with a spray with mean droplet diameter below $25 \mu \mathrm{m}$, injected in a counter-flow configuration. This conclusion requires experimental verification. An additional requirement is that the selected nozzle has to be easily combined to real condensers in refrigerating units. Three nozzle types have been considered for tests and comparisons: a pneumatic nozzle (ref SU1A by Spraying System and Co.), a low pressure hydraulic nozzle (ref TX06 by Spraying System and Co.) and a high pressure hydraulic nozzle (ref C01 by Climext ${ }^{\circledR}$ ). First of all, the characterization has been done through flow rate measurements as a function of feed pressure. All three nozzles may be used in the range of interest for our application: between 1.12 and $1.68 \mathrm{~L} / \mathrm{h}$. This latter value is sufficient in the studied conditions to increase the air humidity up to saturation. Owing to an expected air flow rate between 0.1 and $0.2 \mathrm{~m}^{3} / \mathrm{s}$, (corresponding to an average velocity around 1.1 and
$2.2 \mathrm{~m} / \mathrm{s}$ in the channel) a larger water flow rate would result in an excessive droplet injection, an incomplete droplet evaporation and remaining droplets potentially streaming down the heat exchanger surface (which must be avoided for sanitary reasons linked to legionela purpose for instance). All nozzles provide a conic spray with nearly constant injection angles as a function of the pressure, equal to $54^{\circ}, 18^{\circ}$ and $39^{\circ}$ for the TX06, SU1A and C01 nozzle respectively (based on manufacturer prescriptions and direct measurement performed on pictures carried out on the injected sprays with a camera). Then, the droplet size generated by the nozzle has been evaluated using a Phase Doppler Analyser (PDA) manufactured by Dantec-dynamics ${ }^{\circledR}$ and equipped with a classical reception optics and a P80 signal processor. The laser excitation volume is formed using a LDA transmitter probe (Dantec-dynamics Fiber-Flow $^{\circledR}$ probe). The laser source is an argon ion laser tuned at wavelength $514.5 \mathrm{~nm}$. The receiver is positioned at a scattering angle of $45^{\circ}$ and the PDA is used in the refraction mode. The focal lengths of the transmitter and reception optics are respectively 310 and $500 \mathrm{~mm}$. Thus, the maximum detectable droplet diameter is $180 \mu \mathrm{m}$. Results are presented for the three nozzles as a function of the distance from the injection point (between 5 and $30 \mathrm{~cm}$ along the spray axis below the nozzle), for varying feed pressure (Fig. 3). Results are given in terms of Sauter mean diameter $\left(D_{32}\right)$, often used for spray characterization, which provides a ratio between the global volume of injected liquid water and the interfacial area

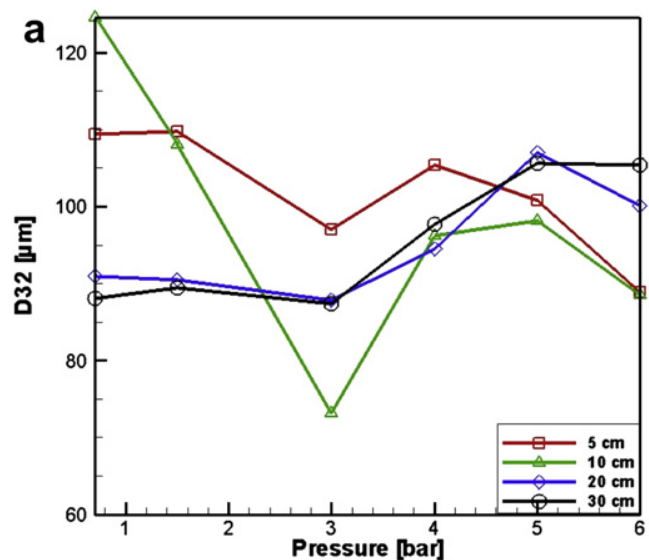

TX06 nozzle (hydraulic low pressure nozzle)

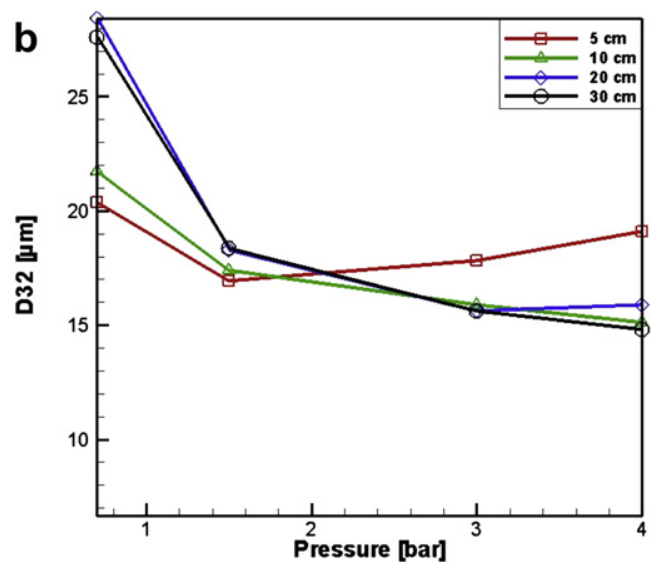

SU1A nozzle (pneumatic nozzle)

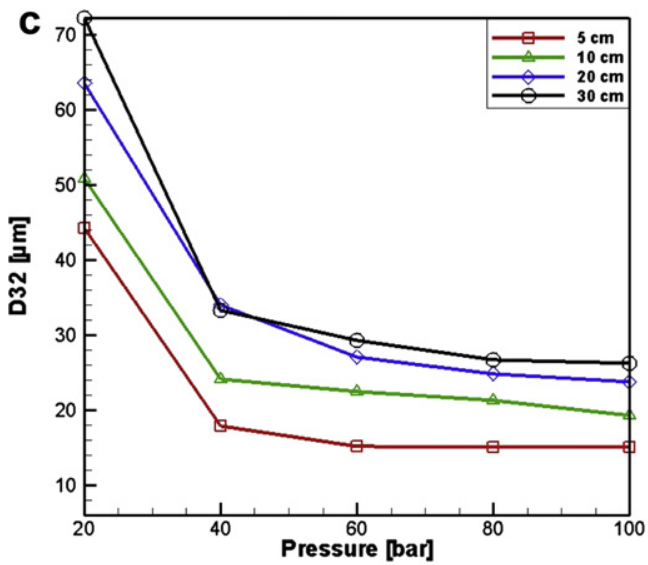

C01 nozzle (hydraulic high pressure nozzle)

Fig. 3. Sauter mean diameter along the spray axis for the three nozzle types, as a function of feed pressure, for increasing distance below the injection point. 
between water and air. The evaluation of the uncertainty regarding the Sauter mean diameter is a complex problem, for which two types of errors have to be considered. The first source of error is related to the measurement itself of the diameter for a given droplet. It can be evaluated through a relationship between the diameter and the emission and reception angles defined on the optical setup. The second error type is linked to the detection thresholds which affect the computation of the statistics and the mean diameter in particular. There is no straightforward formulation for this contribution. However, various experimental detectivity tests can be carried out by changing the photomultiplier high voltages and the electronic gain factor, in order to evaluate the related uncertainty. This work has been done on a similar spray providing a relative uncertainty of $3.5 \%$. This value can be considered as a good indicator of the present uncertainty.

Experimental results are not satisfactory for the present application with the TX06 nozzle (Fig. 3a). First of all, data show that the nozzle at low pressure delivers a low flow rate (not shown here) and too large droplets. These large droplets infer noisy results. In any case, the mean droplet size is always above $80 \mu \mathrm{m}$ and remains far from our requirement of the injection of small droplets with size below $25 \mu \mathrm{m}$.

On the contrary the two other nozzles are potentially satisfactory, yielding a droplet size which globally decreases with the pressure (except at $5 \mathrm{~cm}$ from the injection point with the SU1A, but this is a local measurement, very close to the injection point, with a device providing an injection velocity close to $100 \mathrm{~m} / \mathrm{s}$, which also rises uncertainty problems). Regarding the droplet size, both SU1A and C01 nozzles could be chosen, with an even better performance for the SU1A type. However, this latter nozzle is a pneumatic type, requiring high air pressure and double feed for air and water. For the sake of simplicity, the hydraulic high pressure nozzle has been preferred, considering potential applications in real devices.

A synthesis of the nozzle characteristics is presented in Table 2. The above-mentioned critical data are recalled for measurement $5 \mathrm{~cm}$ below the injection point. The C01 nozzle appears as the best candidate due to a more practical use, a moderate injection velocity (around $29 \mathrm{~m} / \mathrm{s}$ ) and a satisfactory Sauter mean diameter at the injection (the averaged standard diameter $D_{10}$ is also indicated). One interesting feature is that this size remains quite constant on a wide range of water feed pressure (between 40 and 100 bar) meaning that the flow rate can be varied through the pressure feed without altering the droplet size.

Note that the characterization has been performed on a vertical injection in quiet surrounding ambiance, whereas the application will be performed with a horizontal injection in a channel air flow. Results presented in this section are consequently used for the nozzle qualification but the size distribution 20 or $30 \mathrm{~cm}$ after the nozzle cannot be simply used for our application. Numerical validations of our numerical code (see [7]) have been rather conducted considering the distribution measured just after the nozzle $(5 \mathrm{~cm})$, before strong modification owing to the surrounding flow type.

Table 2

Main characteristics of the injected sprays with the 3 nozzle types, evaluated $5 \mathrm{~cm}$ below the injection point keeping the same water flow rate for each nozzle: $(1.4 \mathrm{~L} / \mathrm{h})$

\begin{tabular}{llrllc}
\hline Nozzle & $\begin{array}{l}\text { Pressure } \\
(\text { bar })\end{array}$ & $\begin{array}{l}\text { Droplet velocity } \\
\text { at injection }(\mathrm{m} / \mathrm{s})\end{array}$ & $\begin{array}{l}\text { Angle of } \\
\text { injection } \\
\left({ }^{\circ}\right)\end{array}$ & $\begin{array}{l}\text { Mean diameter } \\
D_{10}(\mu \mathrm{m})\end{array}$ & $\begin{array}{l}\text { Sauter mean } \\
\text { diameter } D_{32} \\
(\mu \mathrm{m})\end{array}$ \\
\hline C01 & 60 & 29 & 38.8 & 10 & 17 \\
TX06 & 1 & 6 & 54 & 78 & 110 \\
SU1A & 1.5 & 100 & 18 & 9 & 18 \\
\hline
\end{tabular}

\section{Experimental results}

\subsection{Air cooling through droplet evaporation}

The pilot has been equipped with the above described nozzles in various conditions for testing their ability to cool the air flow loaded with droplets in an efficient manner. The properties of air at the inlet of the channel section are given in Table 3. The water flow rate has been set to $1.4 \mathrm{~L} / \mathrm{h}$, which corresponds to $85 \%$ of what would be required for achieving the saturation of air in the present conditions. The aim is to provide an actual cooling without excessive liquid water loading that could result in droplet streaming down the heat exchanger surface downstream in the channel. This water flow rate corresponds to a pressure feed around 1 bar with the TX06 nozzle, 1.5 bar with the SU1A (with a $10 \mathrm{~cm}$ siphon height) and 60 bar for the C01 type.

Temperature distributions measured $40 \mathrm{~cm}$ after the injection point, downstream in the channel, are presented in Fig. 4a, for the 3 nozzles, for a co-current injection (left hand side) and countercurrent injection (right hand side). The average temperature in the section is also indicated in the caption in order to give information on the global cooling ability. For the present application, the TX06 nozzle (upper figures) is confirmed to be inefficient as there is no actual cooling of air, as expected due to the too large size distribution of droplets reported in the previous section. On the contrary the two other nozzles provide an obvious cooling up to an average of $3.3 \mathrm{~K}$ and $5.6 \mathrm{~K}$ for the $\mathrm{C} 01$ and the SU1A nozzle respectively, in counter-flow situation. There is a clear difference in the cooling influence depending on the co-current or the counter-current injection choice, which is indicated by the temperature distribution pattern. On the left hand side of Fig. 4, cooling is heterogeneous and only the central section of the channel is really cooled. This can be explained by the droplets entrainment by the air flow, which is important owing to the small inertia of the droplets. Droplets are mainly confined in a restricted area, where the cooling is really strong, as the minimum temperature decreases close to the wet temperature in the best situation. However, the lack of droplet dispersion penalizes the global cooling and results in a decrease of the average temperature, not exceeding $1 \mathrm{~K}$. On the contrary the counter-flow injection allows an efficient droplet dispersion and a strong evaporation occurs in a larger transverse section. This can be also understood through the analysis of Fig. 2 with the differences in the two trajectory patterns. Due to a weaker confinement of the spray in counter-current configuration, the minimum temperature reached is higher but in average the cooling is more efficient. The increase in the residence time of the droplets is a supplementary advantage for the evaporation possibility. For the present application this homogeneous cooling will benefit the whole exchanger surface downstream of the flow, instead of being restricted to the central area. Definitively the counter flow injection is confirmed as the right choice for an efficient cooling, similar to what was numerically predicted in [7].

Table 4 gives a synthesis of the average measurements regarding temperature and humidity for the three nozzles and

Table 3

Air properties at the inlet of the test section.

\begin{tabular}{llllll}
\hline $\begin{array}{l}\text { Water } \\
\text { llow } \\
\text { rate }\left(\mathrm{l} \mathrm{h}^{-1}\right)\end{array}$ & $\begin{array}{l}\text { Air flow } \\
\text { rate } \\
\left(\mathrm{m}^{3} \mathrm{~s}^{-1}\right)\end{array}$ & $\begin{array}{l}\text { Temperature } \\
(\mathrm{K})\end{array}$ & $\begin{array}{l}\text { Relative } \\
\text { humidity } \\
(\%)\end{array}$ & $\begin{array}{l}\text { Absolute } \\
\text { humidity } \\
(\mathrm{g} / \mathrm{kg})\end{array}$ & $\begin{array}{l}\text { Wet } \\
\text { temperature } \\
(\mathrm{K})\end{array}$ \\
\hline 1.4 & 0.1 & 298.2 & 35.0 & 7.0 & 288.4 \\
\hline
\end{tabular}


a

Co-flow

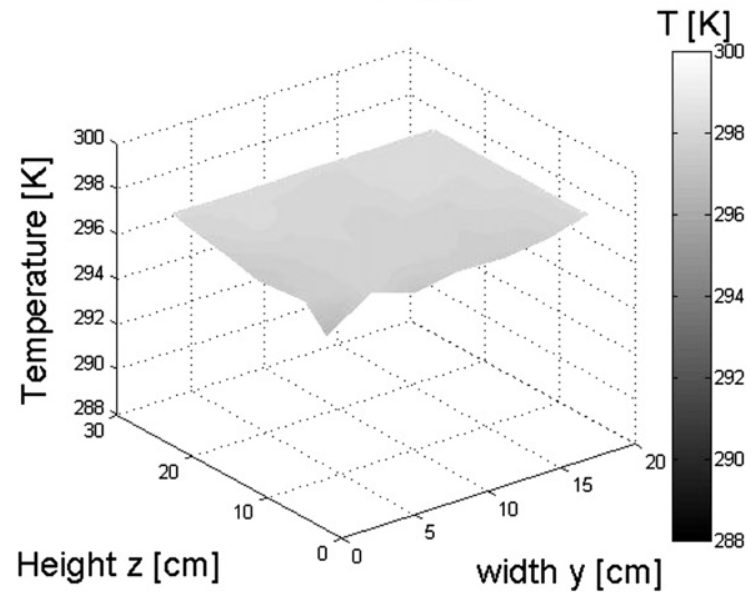

TX06 $\mathrm{T}_{\text {average }}=297.9 \mathrm{~K}$

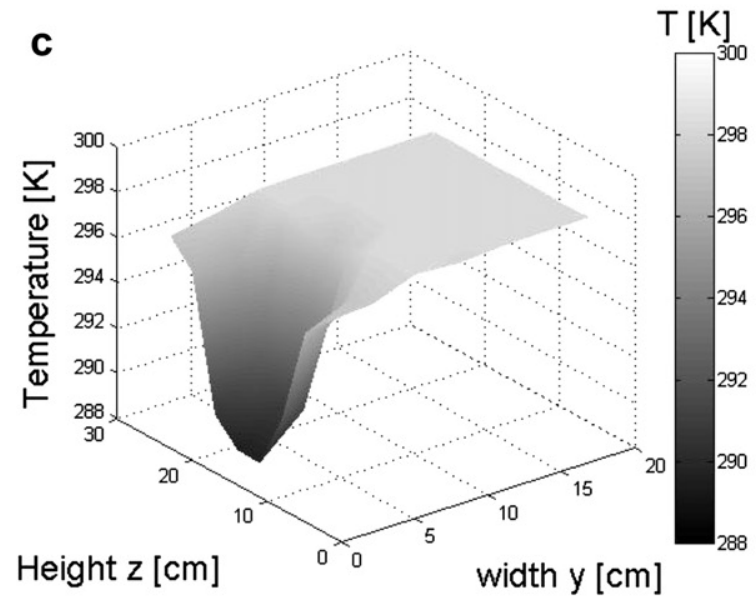

C01 $\mathrm{T}_{\text {average }}=297.2 \mathrm{~K}$

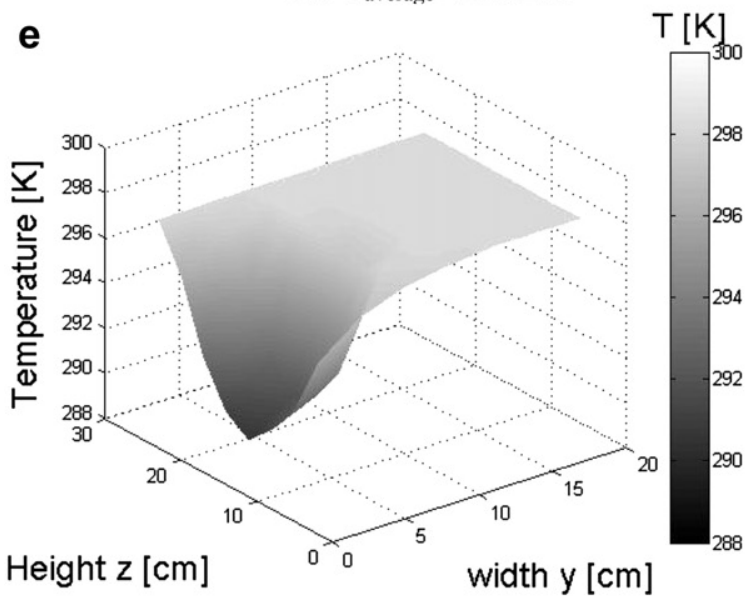

SU1A $T_{\text {average }}=297.2 \mathrm{~K}$ b

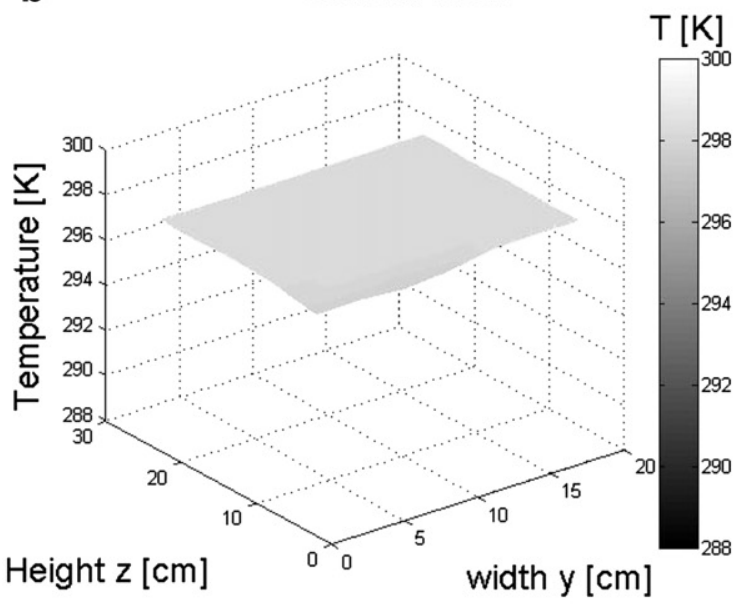

TX06 $_{\text {average }}=298.2 \mathrm{~K}$

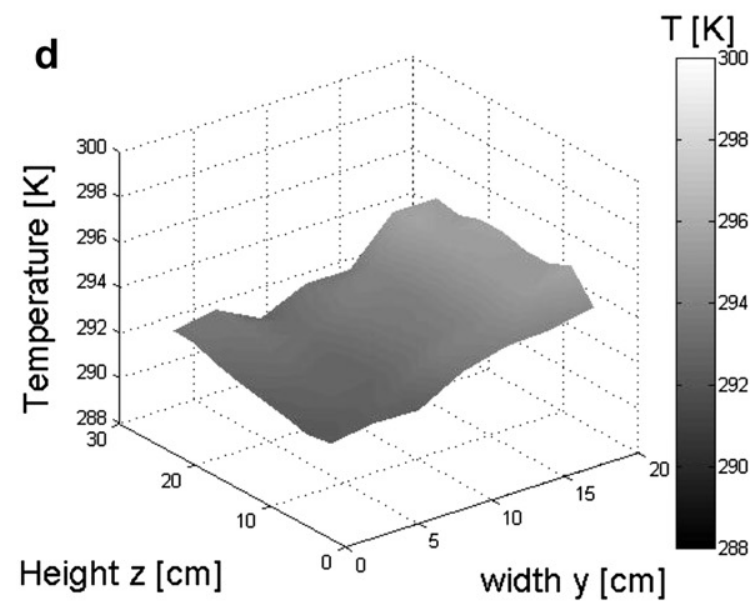

$\mathrm{C} 01 \mathrm{~T}_{\text {average }}=294.9 \mathrm{~K}$

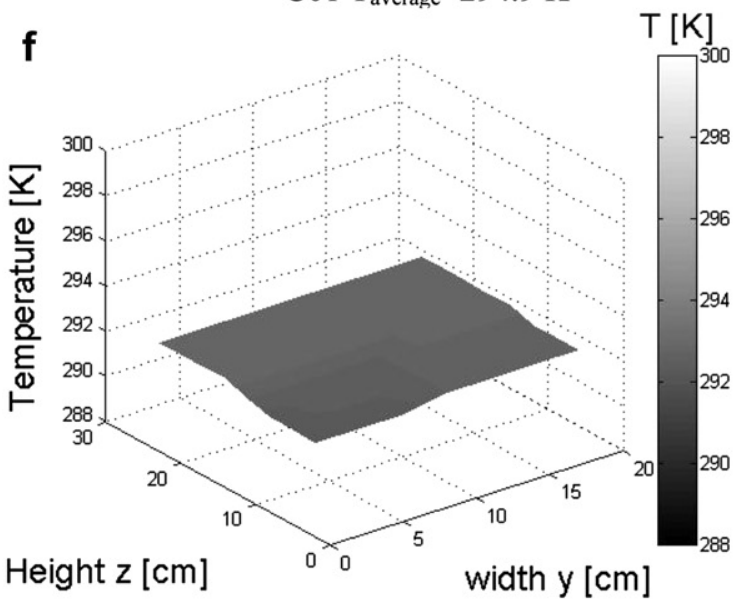

SU1A $T_{\text {average }}=292.6 \mathrm{~K}$

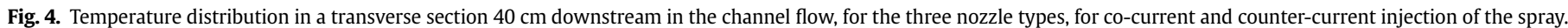
The average temperature in the section is indicated with the nozzle type.

the two injection directions, which confirms the observation of the temperature distribution. A supplementary evaluation of the evaporated water is provided, clearly stating a better evaporation in counter-flow situation and highlighting the best performance of the nozzles which provide the smallest droplets.
Regarding the nozzle selection, the $\mathrm{C} 01$ is confirmed to be a good compromise between efficient cooling (not as good as the one achieved with the pneumatic nozzle, but still really satisfactory with $51 \%$ of evaporated water) and easy of use. Only this nozzle will be kept for the following tests. 
Table 4

Average and extreme temperature and humidity in the downstream flow $40 \mathrm{~cm}$ after injection. The evaporated water rate is also evaluated at the same position.

\begin{tabular}{|c|c|c|c|c|c|c|}
\hline \multirow{2}{*}{$\begin{array}{l}\text { Inlet air properties: } \\
298.2 \mathrm{~K} \& 35 \% \mathrm{RH}\end{array}$} & \multirow[t]{2}{*}{ Nozzle } & \multicolumn{2}{|c|}{ Temperature (K) } & \multicolumn{2}{|l|}{$\mathrm{RH}(\%)$} & \multirow{2}{*}{$\begin{array}{l}\text { Evaporated } \\
\text { water rate } \\
(\%)\end{array}$} \\
\hline & & Average & Min. & Average & Max. & \\
\hline \multirow[t]{3}{*}{ Co-flow } & TX06 & 297.9 & 296.6 & 35.8 & 41.8 & 7.3 \\
\hline & $\mathrm{C} 01$ & 297.2 & 289.5 & 38.9 & 89.4 & 18.3 \\
\hline & SU1A & 297.2 & 290.5 & 38.9 & 80.7 & 18.2 \\
\hline \multirow[t]{3}{*}{ Counter-flow } & TX06 & 298.1 & 297.7 & 35.4 & 36.8 & 3.9 \\
\hline & $\mathrm{C} 01$ & 294.9 & 293.2 & 50.5 & 60.8 & 51.0 \\
\hline & SU1A & 292.6 & 292.2 & 64.8 & 67.6 & 82.6 \\
\hline
\end{tabular}

\subsection{Evolution of air cooling for varying distance downstream the nozzle}

Measurements are now repeated in transverse sections located $5,20,40$ and $60 \mathrm{~cm}$ downstream to the injection position in order to see if evaporation continues after the nozzle, determine the best distance between the nozzle and the heat exchanger and obtain the optimal cooling of the air flow. The same conditions are kept for the air at the inlet and the C01 nozzle is used in counter-flow condition injecting water with a pressure of 60 bar.

The temperature distribution patterns along the channel are very similar and close to the distribution shown on Fig. 3d. The case of the $5 \mathrm{~cm}$ position is only presented on Fig. 5 (left hand side) and is compared to the numerical prediction (right hand side) performed with the numerical simulation detailed in [7]. In the model, the inlet conditions are the same as the experimental ones and the size distribution is the exact size distribution provided by the PDA measurements. There is a good agreement in the distribution patterns, but with some contours which are less regular according to the experimental results as initially expected. Such agreement brings us confidence for the analysis of the numerical simulation results in terms of assumed underlying physical phenomena.

The cooling is observed to be more effective near the central area but it still affects the whole transverse section even close to the nozzle $(5 \mathrm{~cm})$. Actually, the droplet dispersion is due to the counterflow injection and droplets have already experienced a round trip in the air, which governs their trajectory. According to the simulations discussed in [7] and illustrated on Fig. 2, the tracking of the droplets shows that they are dragged by the air flow in a quite linear mean trajectory after flowing twice close to the nozzle. This explains that the droplet distribution only weakly changes downstream and consequently that the air cooling remains quite unchanged.

Regarding the exact improvement of the cooling process as a function of the distance, results are summarized in Table 5. The average temperature and humidity are provided as a function of the distance where the transverse section is scanned. The evaporated water rate is also evaluated. As can be seen, the evaporation process continues to decrease the temperature and to load the air flow in humidity, but the effect is really small. The evaporated water rate remains close to $50 \%$, varying in a small range, obviously close to the uncertainty evaluation. Owing to the decrease of the temperature and also of the difference between the air humidity and the saturation conditions at the droplet surface, the evaporation is not more efficient than what can be observed during the first part of the droplet trajectories.

One consequence of the present test is that there is no need to inject droplets far upstream from the heat exchanger which has to be cooled. A small distance around $5 \mathrm{~cm}$ is enough for an efficient cooling. This is interesting for the compactness of the device. Another advantage is that a spray injected far from the area of interest for the heat exchange could be affected by transverse air flows due to a lateral wind for example. Such application problems will be avoided by placing the nozzle close to the exchanger without really penalizing the upstream air cooling.

\subsection{Influence of the water flow rate and the inlet air flow}

The influence of the water flow rate is now investigated, still for the C01 nozzle with counter-current injection, for three different air inlet conditions. The water supply is set to $1.12,1.4$ and $1.68 \mathrm{~L} / \mathrm{h}$ successively and results are provided for the two transverse sections 5 and $20 \mathrm{~cm}$ downstream the injection point, in order to confirm the observation of the above paragraph. Remember that with the $1.4 \mathrm{~L} / \mathrm{h}$ water flow rate, $85 \%$ of the water required for a theoretical saturation of air is provided when the air flow rate is $0.1 \mathrm{~m}^{3} / \mathrm{s}$. The other water flow rates correspond to a variation by +1 $-20 \%$ of this value, corresponding to 68 and $101 \%$ of the water required for saturating the air. The maximum flow rate of $1.68 \mathrm{~L} / \mathrm{h}$ should therefore provide the air saturation if the droplet evaporation is complete. The inlet air temperature is kept constant while
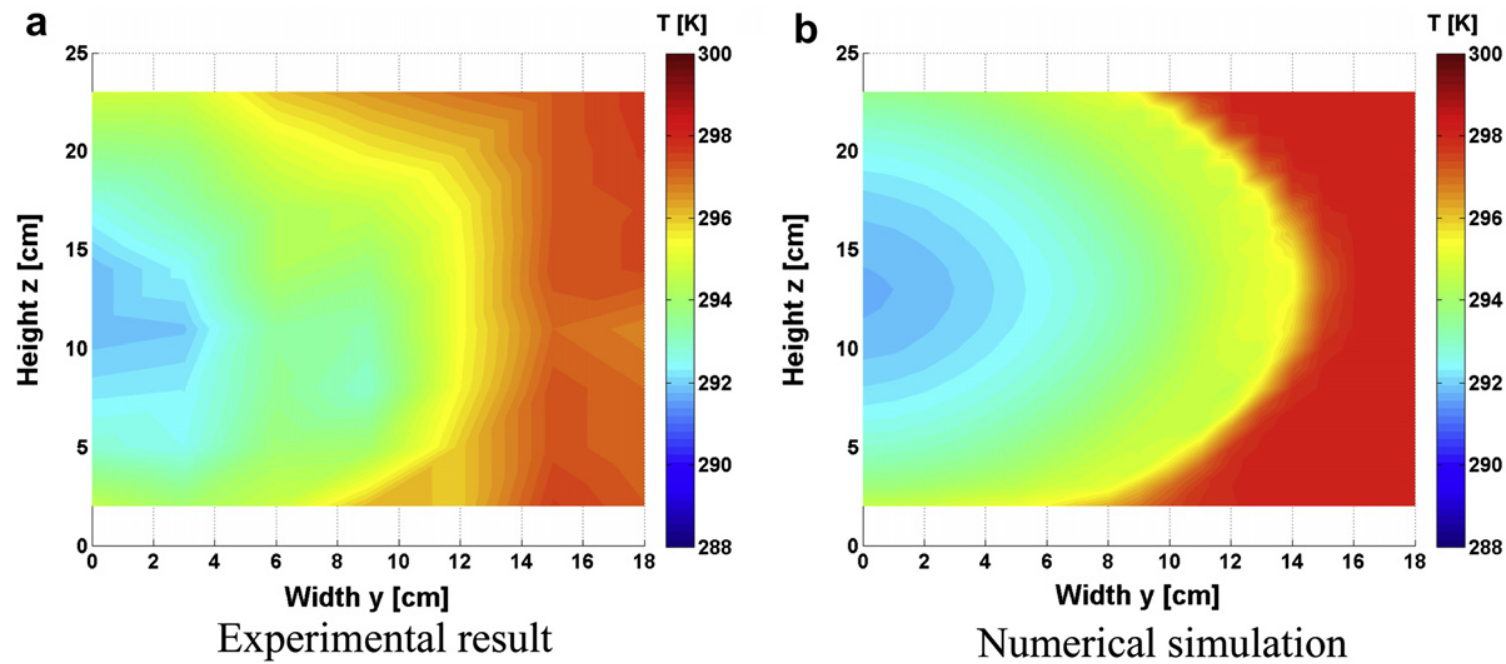

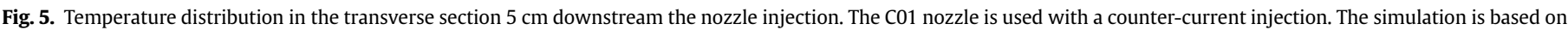
the code described in [7]. 
Table 5

Average and extreme temperature and relative humidity in the downstream flow, measured at four locations downstream in the flow after the injection point. The evaporated water rate is also evaluated at the same positions.

\begin{tabular}{lllllll}
\hline \multirow{2}{*}{$\begin{array}{l}\text { Distance } \\
(\mathrm{cm})\end{array}$} & \multicolumn{2}{l}{ Temperature $(\mathrm{K})$} & & \multicolumn{2}{l}{ RH $(\%)$} & \multirow{2}{*}{$\begin{array}{l}\text { Evaporated water } \\
\text { rate }(\%)\end{array}$} \\
\cline { 2 - 3 } & Average & Min & & Average & Min & \\
\hline 5 & 295 & 291.8 & & 50.3 & 70.9 & 49.4 \\
20 & 295.1 & 293.2 & & 49.8 & 61.2 & 47.1 \\
40 & 294.9 & 293.2 & & 50.9 & 61.2 & 51.0 \\
60 & 294.8 & 293.2 & & 51.5 & 61.2 & 51.3 \\
\hline
\end{tabular}

increasing the air flow rate up to 0.15 and $0.2 \mathrm{~m}^{3} / \mathrm{s}$. The inlet relative humidity is then set to jeep a constant ratio between the water flow rate used and that which is necessary for the air saturation. Whatever the air flow rate, 68,85 and $101 \%$ of the required water are still provided, corresponding to a prescribed relative humidity of inlet air equal to $35 \%, 55 \%$ and $65 \%$ respectively for the three air flow rates considered.

Regarding the experimental results obtained in these different cases, no major modifications are observed on the temperature distributions (consequently not shown here). They are close to those observed and commented above. In particular, the ability to cool all the transverse section in a satisfactory homogeneous manner is confirmed in every case. However, this advantage of the counter-flow injection is slightly penalized by an increase in the air flow rate, because droplets are dragged more efficiently with higher air velocities, which lead them to a more confined area and decrease their residence time. The temperature distributions seem to be similar, but there are some effects on the cooling which can appear on data averaged on transverse sections, as summarized in Table 6 and in the following items:

- the cooling is obvious, reaching $5 \mathrm{~K}$ in the best case for air flow rate of $0.1 \mathrm{~m}^{3} / \mathrm{s}$ and the highest water flow rate (the dryest the air is, the most efficient the cooling is, as a logical consequence of evaporation);

- for a given air flow rate, the increase in the water supply logically increases the cooling (decrease in temperature combined with a humidity increase), but the air saturation is never reached, even with the theoretical water supply required for achieving saturation;

- for a given spray flow rate, an increase in the air velocity penalizes the evaporation due to a stronger droplet entrainment resulting in a smaller residence time and a more confined spray (in particular because droplet dispersion is less efficient as it is observed on simulations).

- the distance from the injection point has a very weak influence and air properties do not change much downstream the nozzle position (as observed in the previous section)

\section{Enhancement of heat exchange with a sprayed air flow}

In order to demonstrate the potential gain for the heat exchanges downstream to the injection point with the sprayed air flow, a heat exchanger fed with hot water has been used, as presented on Fig. 1 at the outlet of the channel. The heat exchanged can easily be quantified by measuring the water flow rate inside the exchanger and the water temperature difference between inlet and outflow on the water side. The water flow rate is obtained with a flowmeter (ref Promag 33 by Profibus PA company) and the water temperature is measured using PT100 sensors (ref SL3504f-15m by Prosensor). The uncertainty on the heat exchanged has been evaluated owing to the errors attributed to both measurement techniques $(+/-0.1 \mathrm{~K}$ after calibration and measurement dispersion analysis for the temperature and $+\mid-0.3 \%$ for the water flow rate) Values presented below for the heat exchanged have been obtained with a maximal uncertainty of $+/-70 \mathrm{~W}$ for a measurement range between 500 and $1000 \mathrm{~W}$ (depending on the air inlet temperature)

For a supplementary demonstration of the advantage provided by the spraying of air upstream from the exchanger, Fig. 6 shows the temperature decrease obtained with the spraying technique as a function of the inlet air temperature. The temperature difference obtained between the inlet and the outlet of the channel is plotted for three water flow rates. The conditions of the study have been chosen such as keeping constant the absolute humidity of air at the inlet while varying its temperature, with the reference case of an inlet temperature at $298.6 \mathrm{~K}$ and a relative humidity of $33 \%$. The temperature decrease due to air cooling cannot be directly taken or extrapolated from the results of the previous paragraph, because of the presence of the heat exchanger which is located just downstream the nozzle. The case of the C01 nozzle in counter-flow injection condition has been chosen as a logical follow up to the above section analysis. The nozzle is located $5 \mathrm{~cm}$ upstream from the heat exchanger for compactness consideration as abovediscussed. The air flow rate is $0.1 \mathrm{~m}^{3} / \mathrm{s}$.

As can be seen, a temperature decrease up to $8 \mathrm{~K}$ has been achieved in the most favoring case (dryest and hotest conditions at the inlet for the air with $20 \%$ of relative humidity and temperature

Table 6

Influence of the water flow rate and of the inlet air conditions on the cooling and the loading in humidity.

\begin{tabular}{|c|c|c|c|c|c|}
\hline Inlet air conditions at $298.2 \mathrm{~K}$ & $\begin{array}{l}\text { Spray flow } \\
\text { rate }(\mathrm{L} / \mathrm{h})\end{array}$ & $\begin{array}{l}\text { Distance from } \\
\text { injection }(\mathrm{cm})\end{array}$ & $\begin{array}{l}\text { Averaged } \\
\text { temperature }(\mathrm{K})\end{array}$ & $\begin{array}{l}\text { Averaged } \\
\text { humidity (\%) }\end{array}$ & $\begin{array}{l}\text { Evaporated } \\
\text { water }(\%)\end{array}$ \\
\hline \multirow{6}{*}{$\begin{array}{l}\text { Flow rate: } 0.1 \mathrm{~m}^{3} / \mathrm{s} \text { Relative } \\
\text { humidity: } 35 \%\end{array}$} & \multirow[t]{2}{*}{1.12} & 5 & 295.3 & 48.8 & 55.9 \\
\hline & & 20 & 295.3 & 48.8 & 55.7 \\
\hline & \multirow[t]{2}{*}{1.4} & 5 & 295.0 & 49.9 & 47.2 \\
\hline & & 20 & 295.1 & 49.3 & 49.4 \\
\hline & \multirow[t]{2}{*}{1.68} & 5 & 293.0 & 62.0 & 65.5 \\
\hline & & 20 & 293.0 & 62.0 & 65.2 \\
\hline \multirow{6}{*}{$\begin{array}{l}\text { Flow rate: } 0.15 \mathrm{~m}^{3} / \mathrm{s} \text { Relative } \\
\text { humidity: } 55 \%\end{array}$} & \multirow[t]{2}{*}{1.4} & 5 & 296.7 & 63.2 & 38.5 \\
\hline & & 20 & 296.9 & 62.0 & 34.6 \\
\hline & \multirow[t]{2}{*}{1.68} & 5 & 296.3 & 65.6 & 40.2 \\
\hline & & 20 & 296.4 & 65.0 & 37.7 \\
\hline & \multirow[t]{2}{*}{1.12} & 5 & 296.2 & 66.2 & 35.5 \\
\hline & & 20 & 295.9 & 68.2 & 40.1 \\
\hline \multirow{6}{*}{$\begin{array}{l}\text { Flow rate: } 0.2 \mathrm{~m}^{3} / \mathrm{s} \text { Relative } \\
\text { humidity: } 65 \%\end{array}$} & \multirow[t]{2}{*}{1.12} & 5 & 297.2 & 69.8 & 36.1 \\
\hline & & 20 & 297.5 & 67.9 & 26.6 \\
\hline & \multirow[t]{2}{*}{1.4} & 5 & 297.1 & 70.4 & 32.0 \\
\hline & & 20 & 297.1 & 70.4 & 31.5 \\
\hline & \multirow[t]{2}{*}{1.68} & 5 & 296.5 & 74.4 & 38.4 \\
\hline & & 20 & 296.5 & 74.4 & 38.6 \\
\hline
\end{tabular}




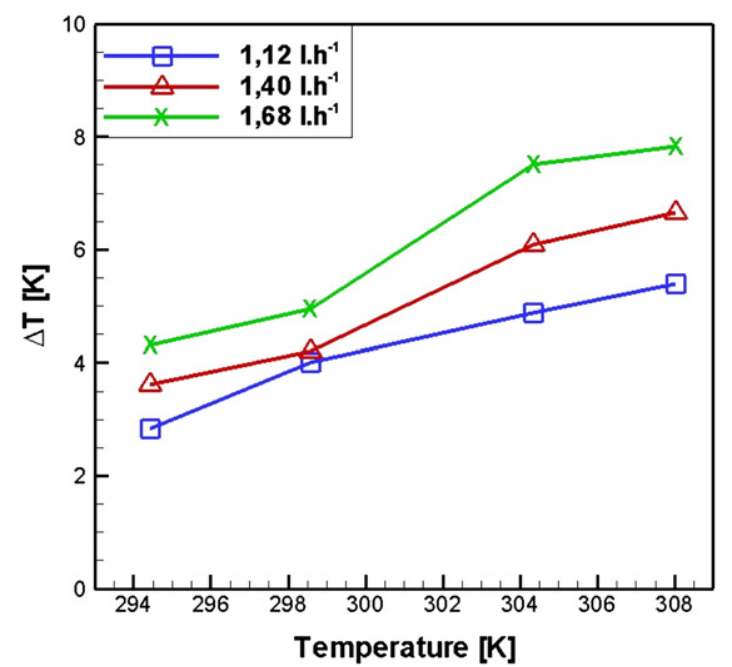

Fig. 6. Temperature cooling upstream the heat exchanger as a function of inlet air temperature: the difference is plotted between the average temperature at the inlet section of the channel and the temperature at the location of the exchanger, for three studied water flow rates.

Table 7

Ratio of heat exchanged with the sprayed air flow over heat exchanged without spraying, for given air inlet temperatures and water flow supplies. Reference data are given on the second line in terms of heat exchanged without spray.

\begin{tabular}{|c|c|c|c|c|}
\hline & \multicolumn{4}{|c|}{$\begin{array}{l}\text { Air inlet temperature in the channel upstream } \\
\text { from the injection point }\end{array}$} \\
\hline & $294.4 \mathrm{~K}$ & $298.6 \mathrm{~K}$ & $304.4 \mathrm{~K}$ & $308.0 \mathrm{~K}$ \\
\hline $\begin{array}{l}\text { Reference data of heat } \\
\text { exchanged without } \\
\text { spray }\end{array}$ & $650 \mathrm{~W}$ & $499 \mathrm{~W}$ & $285 \mathrm{~W}$ & $149 \mathrm{~W}$ \\
\hline Water flow rate $1.12 \mathrm{~L} / \mathrm{h}$ & 1.27 & 1.39 & 1.74 & 2.93 \\
\hline Water flow rate $1.40 \mathrm{~L} / \mathrm{h}$ & 1.30 & 1.45 & 1.88 & 3.13 \\
\hline Water flow rate $1.68 \mathrm{~L} / \mathrm{h}$ & 1.35 & 1.52 & 2.11 & 3.53 \\
\hline
\end{tabular}

$308 \mathrm{~K})$. As expected, the highest the injected water flow is, the more efficient the cooling is. A confirmation is provided for the capability to cool the air upstream from the exchanger. Therefore, this justifies how heat transfer can improve.

As a preliminary confirmation, the gain achieved in the heat transferred is presented in Table 7 for various air inlet temperature and water spray flow rates. Results are presented in terms of a gain equal to the ratio between the actual heat exchanged with the sprayed air flow, over a reference value without spraying. The reference value of heat exchanged without spray is also given for a better evaluation of the actual gain. As can be seen, this gain may reach values above 3 in the present conditions and is at least equal to 1.27 in the worst situation. The gain is immediately strong when the air is hot and dry at the inlet, as it could be expected. The interest of increasing the water flow also appears, as the gain increases with the water supply to the nozzle. However the optimization of the process would be to find a compromise between the gain in energy achieved with the spray and the water consumption.

Such optimization could be addressed in a further study on the exchanges and will be now conducted using the pilot for an extended experimental work in association with a model for the heat exchanges inside the condenser.

\section{Concluding remarks}

An experimental study of a sprayed air flow has been carried out in a pilot where water droplets have been injected in various conditions in a channel air flow. Three nozzle types have been studied, in co-current and counter-current flow situation. The sprayed air flow has been characterized in terms of cooling of the air and loading in humidity. This cooling has been also investigated as a function of the distance from injection point and for various air or water flow rates. The main conclusions are the following:

- the cooling of air reached $8 \mathrm{~K}$ in the most favoring case studied here (for air with $20 \%$ of relative humidity and temperature $308 \mathrm{~K}$ for a moderate liquid water supply of $1.68 \mathrm{~L} / \mathrm{h}$ ), varying with temperature and humidity conditions;

- there is experimental evidence supporting that cooling is more efficient for a counter-flow injection, using small droplets (typically below $25 \mu \mathrm{m}$ in average at the injection point);

- a co-current injection is less efficient due to a bad dispersion of the droplets so that the minimum temperature reached in the sprayed flow is lower, and the cooling is strongly heterogeneous as well as restricted to a central area;

- on the contrary, a counter-flow injection promotes droplet dispersion resulting in a wider exchange and a more efficient cooling of air in average, also favored by a longer residence time for droplets;

- in that case, there is no need to place the nozzle far from the surface which has to be cooled: the cooling is only slightly better in the spray region downstream to the injection point;

- the numerical simulation performed in a companion study prior to the present experimental work has been further validated, through temperature distributions and averaged values in sections transverse to the channel;

- the gain achieved for a heat exchanger has been observed to reach values up to 3 times the value without spraying, when using a sprayed air flow upstream from the condenser.

Further studies in this experimental setup include the quantification of the heat exchange improvement in a condenser when using sprayed air flow. A systematic work on the optimal water consumption will be carried out using both the pilot and a dedicated heat transfer model for the exchanger. Moreover, the next step will be the application of the present insights to a real refrigerating machine.

\section{Acknowledgments}

The authors are grateful to the ADEME (Agence de l'Environnement et de la Maîtrise de l'Energie) for the financial support of this work. The authors also thank Climext ${ }^{\circledR}$ for lending them the spray generation system and Brumisud for their field experience.

\section{References}

[1] W. Nakayama, H. Kuwahara, S. Hirasawa, Heat transfer from tube banks to air/ water mist flow, Int. J. Heat Mass Transf. 31 (1988) 449-460.

[2] A.A. Dreyer, D.E. Kriel, P.J. Erens, Analysis of spray cooled finned tube heat exchangers, Heat Transf. Eng. 13 (1992) 53-71.

[3] M. Youbi-Idrissi, H. Macchi-Tejeda, L. Fournaison, J. Guilpart, Numerical model of a sprayed air-cooled condenser coupled to a refrigerating system, Energy Convers. Manage. 48 (7) (2007) 1943-1951.

[4] E. Hajidavalloo, H. Eghtedari, Performance improvement of air-cooled refrigeration system by using evaporatively cooled air condenser, Int. J. Refrig. 33 (2010) 982-988.

[5] F.W. Yu, K.T. Chan, Improved energy performance of air-cooled chiller system with mist pre-cooling mist improvement on air-cooled chillers, Appl. Therm. Eng. 31 (2011) 537-544.

[6] M.G. Vrachopoulos, A.E. Filios, G.T. Kotsovielos, E.D. Kravvaritis, Incorporated evaporative condenser, Appl. Thermal Engineering 27 (2007) 823-828.

[7] J. Tissot, P. Boulet, F. Trinquet, L. Fournaison, H. Macchi-Tejeda, Air cooling by evaporating droplets in the upstream flow of a condenser, Int. J. Therm. Sci. 50 (2011) 2122-2131.

[8] Tissot J. Amélioration des performances énergétiques et environementales des systèmes frigorifiques au moyen de la brumisation des condenseurs. PhD Thesis, Université Henri Poincaré, Nancy, France. 2011. 